\title{
Role of Liposuction Combined with Subcutaneous Mastectomy in the Surgical Treatment of Gynecomastia
}

\author{
Md. Sohaib Akhtar, AH Khan, Rabeya Basari', M Fahud Khurram, Imran Ahmad, Saquib Azmi \\ Post Graduate Department of Burns, Plastic and Reconstructive Surgery, 'Department of Pathology, Jawaharlal Nehru Medical College, Aligarh \\ Muslim University, Aligarh, Uttar Pradesh, India
}

\section{A B S T R A C T}

Background: Gynecomastia is one of the common benign male breast diseases, surgical treatment of which remains a controversial issue. Here, we describe successful combined use of liposuction and subcutaneous mastectomy in the treatment of gynecomastia. Aim: To evaluate the effectiveness of the liposuction combined with subcutaneous mastectomy in the treatment of gynecomastia. Materials and Methods: In this retrospective study, a total of 28 patients were included. All the patients had undergone detailed clinical evaluation and appropriate investigations. Information regarding age of onset, etiology, laterality, nipple discharge was collected from patient's medical records. Twenty of 28 patients had unilateral gynecomastia whereas 8 patients had bilateral gynecomastia. Based on the clinical evaluation and investigations, secondary causes of gynecomastia were ruled out. Subcutaneous mastectomy using infraareolar skin incision combined with liposuction was performed on 26 patients. Two patients underwent only liposuction. Results: Twenty-four patients (86\%) were satisfied with the results of the operative intervention. In $24 / 28$ patients ( $86 \%$ ), the indication of surgery was cosmetic reasons and in $4 / 28$ patients (14\%), the indication was failure to treatment with danazol. Average age of the patients was 24 (6) years and most of the patients were between 20 and 30 years of their age. The postoperative complications include infection in two patients and contour deformity in two other patients. Conclusions: Liposuction combined with subcutaneous mastectomy is a reliable, versatile, less time consuming and valid procedure for the treatment of gynecomastia. This procedure provides satisfactory aesthetic results.

KEY WORDS: Gynecomastia, liposuction, subcutaneous mastectomy

\section{INTRODUCTION}

Benign enlargement of the male breast is called gynecomastia. ${ }^{[1]}$ It accounts for $35-65 \%$ of lesions in male breasts that depends on age group and diagnostic criteria of gynecomastia. ${ }^{[2,3]}$ The gynecomastia has increasingly become common in recent years. The possible inciting factors could be anabolic steroids, exposure to xenoestrogens present in cosmetic products, pesticides, and industrial chemicals. ${ }^{[4]}$ Gynecomastia can be true which is proliferation of ductal and periductal tissue and false (pseudogynecomastia) in which only deposition of adipose tissue occurs. ${ }^{[1]}$ Majority of gynecomastia has idiopathic origin ${ }^{[3]}$ while some of them are caused by hormonal imbalance. ${ }^{[1]}$ This could be due to increased estrogen, decreased androgen, defects in the receptor, or an altered estrogen sensitivity of the breast. ${ }^{[3]}$

\begin{tabular}{|l|l|}
\hline \multicolumn{2}{|c|}{ Access this article online } \\
\hline Quick Response Code & $\begin{array}{l}\text { Website: } \\
\text { www.jbcrs.org }\end{array}$ \\
\cline { 2 - 2 } & DOI: \\
& $* * *$ \\
\hline
\end{tabular}

There is wide range of surgical procedure available for the treatment of gynecomastia but it is difficult to choose a single procedure that may give the best outcome. Many techniques showing unacceptable cosmetic results have widely been used despite advances in surgical technology. ${ }^{[5]}$

Subcutaneous mastectomy is one of the common procedures performed with an infraareolar approach, which can be extended laterally depending upon requirement. ${ }^{[5]}$

It has high complication rate including hematoma and seroma formation, contour irregularities, disfigured scars and reduced nipple sensibility. ${ }^{[6-8]}$

Due to frequent complications and disappointing results, this procedure has often been underrated. Suction-assisted liposuction was first described and used by Illouz. ${ }^{[9]}$ Since its inception, it has widely been used allowing better

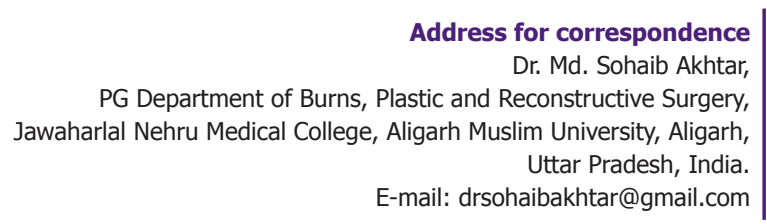


contouring and minimal scarring. On proper planning and meticulous dissection, these modalities can provide satisfactory cosmetic results with minimal complications. To the best of our knowledge, there are a few publications focusing the present combined procedure for surgical treatment of gynecomastia.

\section{MATERIALS AND METHODS}

In this retrospective study, a total of 28 patients were included. Permission for the study was given by the relevant authority. All the patients had undergone detailed clinical evaluation and appropriate investigations. Information regarding age of onset, etiology, laterality, nipple discharge was collected from patient's medical records. Twenty of 28 patients had unilateral gynecomastia whereas 8 patients had bilateral. Based on the clinical evaluation and investigations, secondary causes of gynecomastia were ruled out. All the patients were in Simon's grade I and II.

History of the use of medication, alcohol, symptoms of hepatic and pulmonary as well as sexual dysfunction was taken. During examination, signs of liver, thyroid, lung and renal disease were recorded. Examination of breast and testis was performed and signs of secondary gynecomastia were ruled out. On palpation of breast, a difference was made between true gynecomastia and pseudo-gynecomastia. All the patients with true gynecomastia underwent through investigation. Both liposuction and subcutaneous mastectomy was performed on 26 patients. Two patients underwent only liposuction.

\section{Surgical technique}

Preoperatively enlarged breasts were marked in standing position [Figures 1a and 1b, 2a, 3a, 4a]. All the patients underwent surgery under general anesthesia. Using tumescence technique, breasts were infiltrated with normal saline, $1 \%$ lidocaine and adrenaline solution.

After 5-10 minutes, a semicircular incision was made along the inferior border of nipple areola complex between 3 O' clock and 9 O'clock position [Figures 1c, 2b]. Using $4 \mathrm{~mm}$ and $3 \mathrm{~mm}$ cannula, fatty tissue was suctioned through the same incision. Suctioning was continued till no fat was coming into the cannula. Intraoperatively, breasts were inspected to see the symmetry. Then, breasts were manually palpated to find out the glandular tissue. On its presence, we proceed with subcutaneous mastectomy through the same incision.

Initially, dissection was performed inferiorly up to the preoperatively marked line. Then incision was deepened down to the pectoral fascia and dissection extended superiorly up to the marked line preserving $1 \mathrm{~cm}$ cuff of tissue beneath the nipple-areola complex. Following dissection, breast tissue was excised and following procedures were performed:

- The pectoral fascia was left intact

- Closure was done in two layers after inserting the suction drain; [Figures 1d, 3b]

- Antiseptic dressing was done

- Elastic bandage was used for dressing; and

- All the specimens were sent for histopathological examination.

\section{RESULTS}

All the patients were evaluated in terms of indication of surgery, satisfaction, age range and complications. In $24 / 28$ patients $(86 \%)$, the indication of surgery was for cosmetic reasons while in $4 / 28$ patients $(14 \%)$, the indication was due to the failure of the treatment with danazol. Twenty-four patients (86\%) were satisfied with the results of the operative intervention [Figure $1 \mathrm{~g}$ ]. Mean age of the patients was $24( \pm 6)$ years; most of them were between 20 and 30 years old. The postoperative complications include infection in two patients and contour deformity in two patients. No hematoma or seroma were observed in any of the subjects. Histopathological findings were suggestive of benign lesion in all the cases. Average follow-up period was 6 months (range 3 months to 14 months), during which no recurrence was noticed.

All data analysis was conducted using SPSS software (SPSS Inc.). The continuous parameters were calculated as Mean \pm SD.

\section{DISCUSSION}

Gynecomastia is one of the common problems in young adult male. Surgical treatment of this disease has been a contentious issue. A number of surgical modalities are available for the treatment of gynecomastia. However, the combined use of liposuction and open excision in the surgical treatment of gynecomastia was first introduced by Teimourian and Perlman. ${ }^{[10]}$ Since then, this combined method has widely been in vogue due to the various problems occurred in the use of liposuction alone. ${ }^{[1-13]}$

In this series, we have used liposuction in combination with subcutaneous mastectomy in 28 patients showing good outcomes in terms of cosmetically acceptable appearance and complications [Figures 1e-f, 3b, 4b]. It is important to differentiate physiological gynecomastia from secondary gynecomastia due to some underlying disease and operative treatment is advised only when it is indicated. ${ }^{[14]} \mathrm{A}$ majority of patients with gynecomastia have no underlying disease..$^{[15]}$

In secondary gynecomastia, the underlying disease is 
treated. In our study we excluded all the cases of secondary gynecomastia. Surgical treatment of gynecomastia is indicated in case of failed medical treatment, long-lasting disease, or for cosmetic reason as per the desire of the

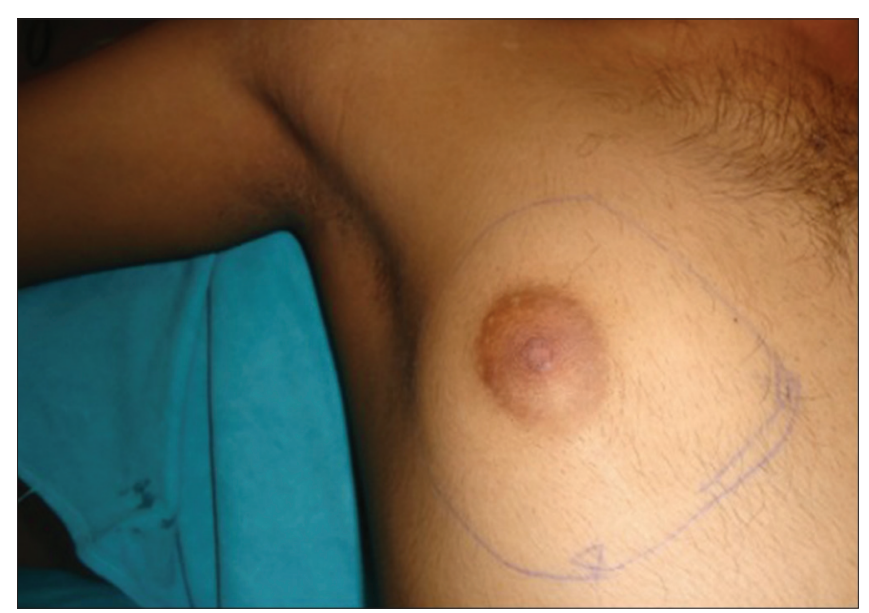

Figure 1a: Preop photograph showing right sided gynecomastia

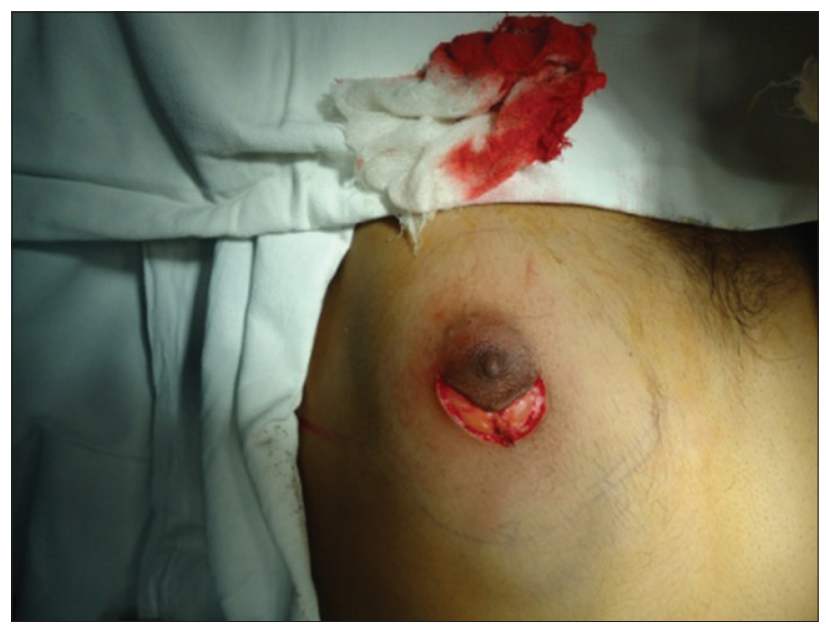

Figure 1c: Infraareolar incision between 3 o'clock and 9 o'clock position(first patient)

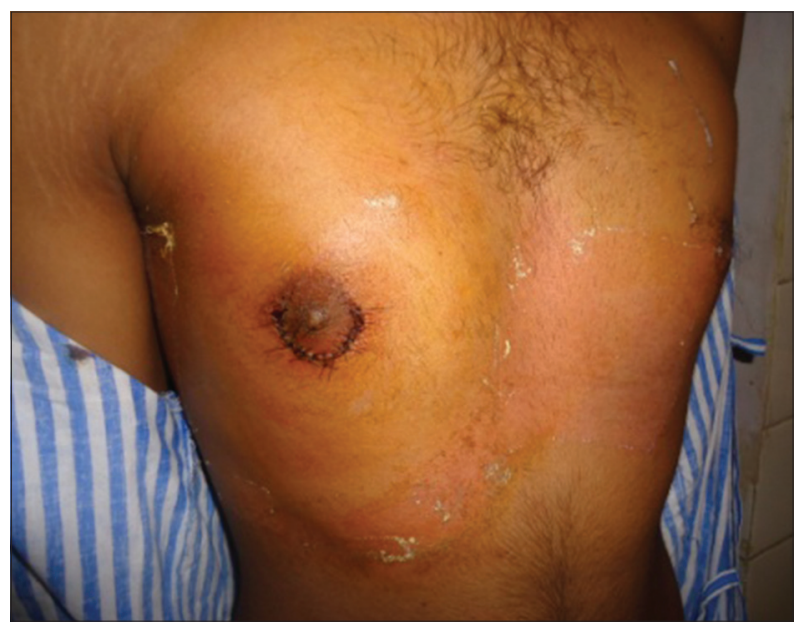

Figure 1e: Postop photograph at day 7 patient. ${ }^{[16]}$

We find in our study that the indication of surgery was for

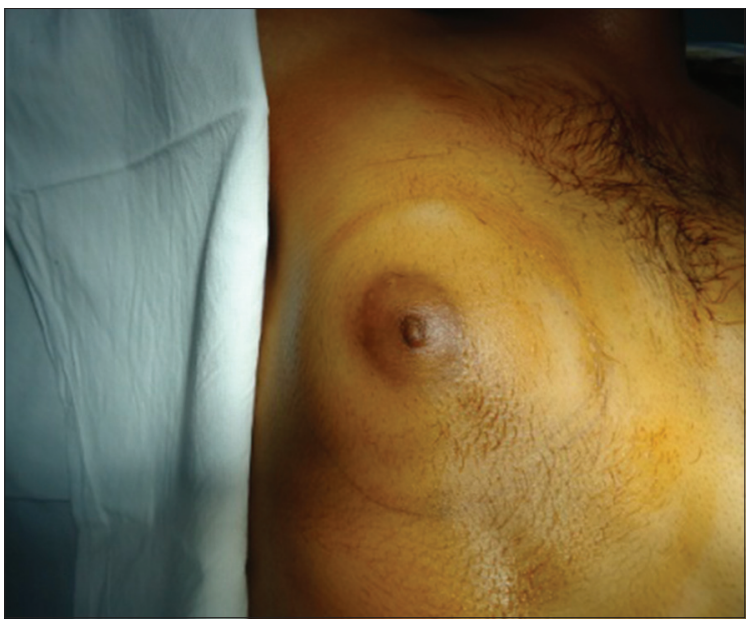

Figure 1b: Another preop photograph after painting, drapping and hair shaving

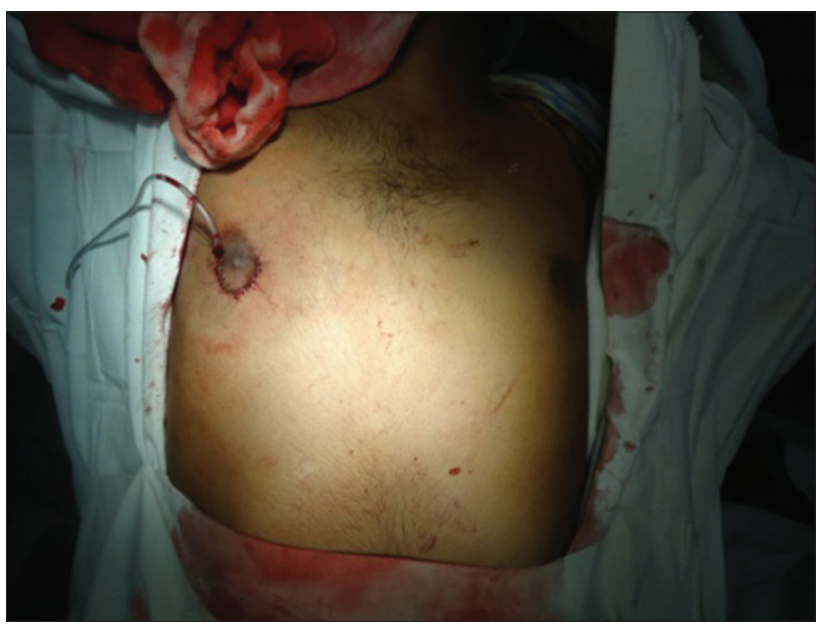

Figure 1d: Immediate post op photograph with suction drain in situ taken through the same incision

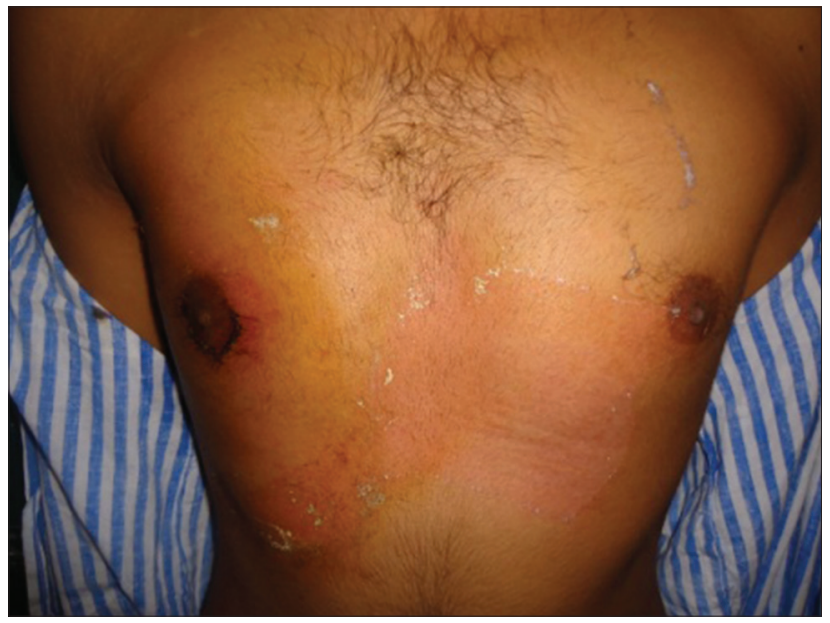

Figure 1f: Postop photograph at day 7 (ap view) 


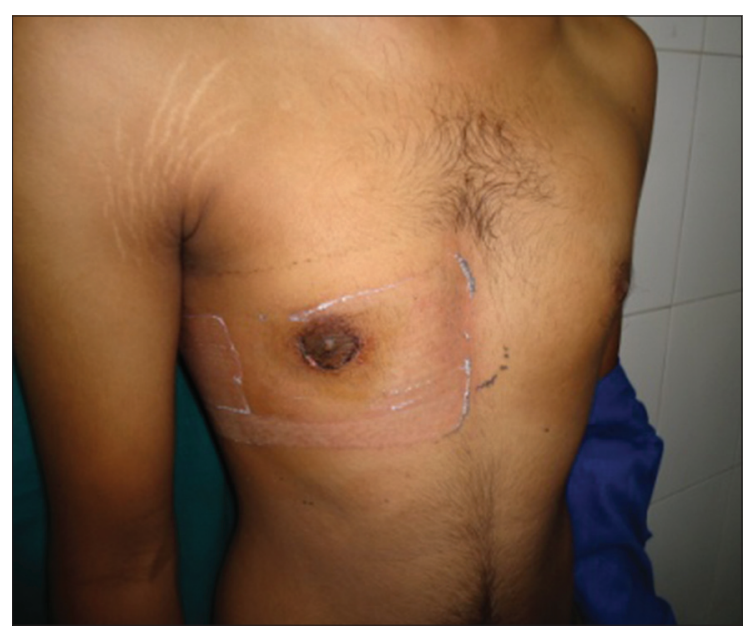

Figure 1g: Postop photograph after stitch removal

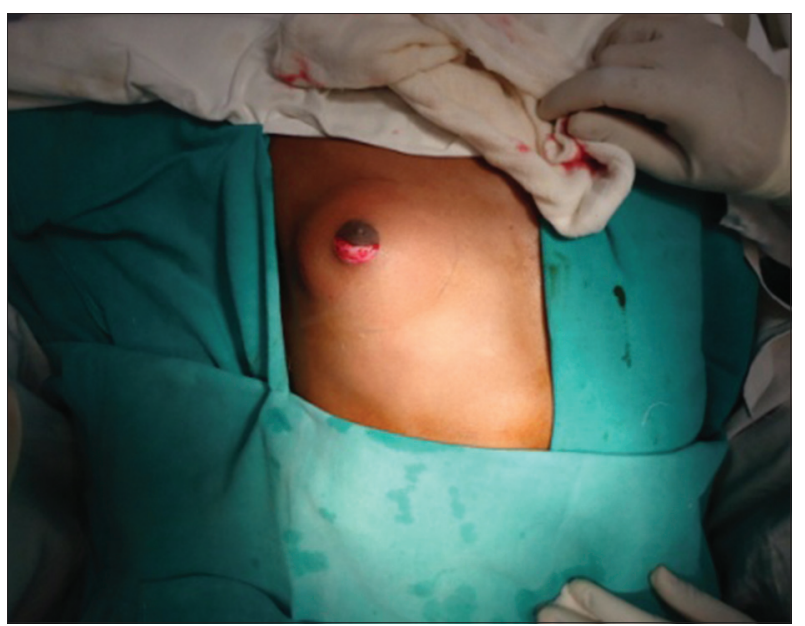

Figure 2b: Infraareolar incision between 3 o'clock and 9 o'clock position (Second patient)

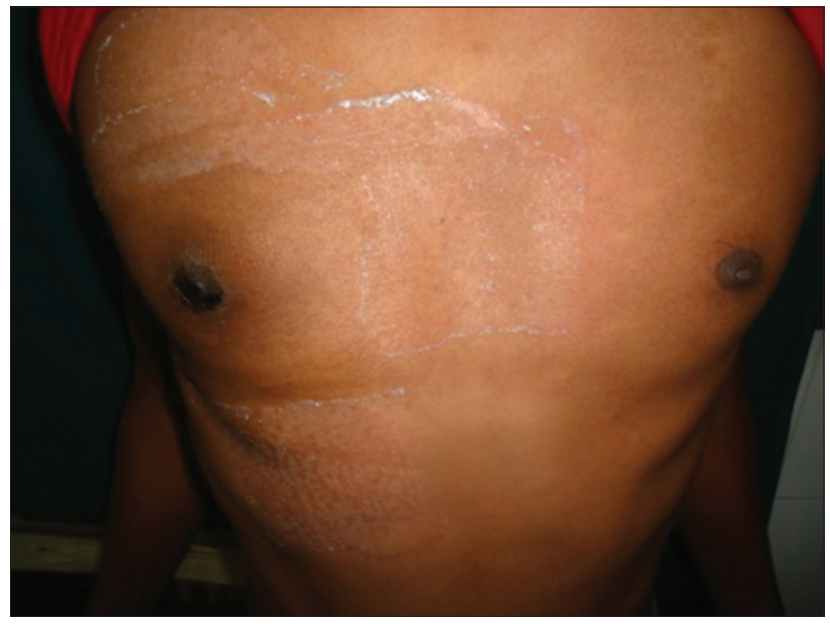

Figure 3b: Postop photograph

cosmetic reasons in 20 patients $(71 \%)$ while in 4 patients (14\%), the indication was due to the failure of danazol treatment.

Several researchers found that liposuction is the

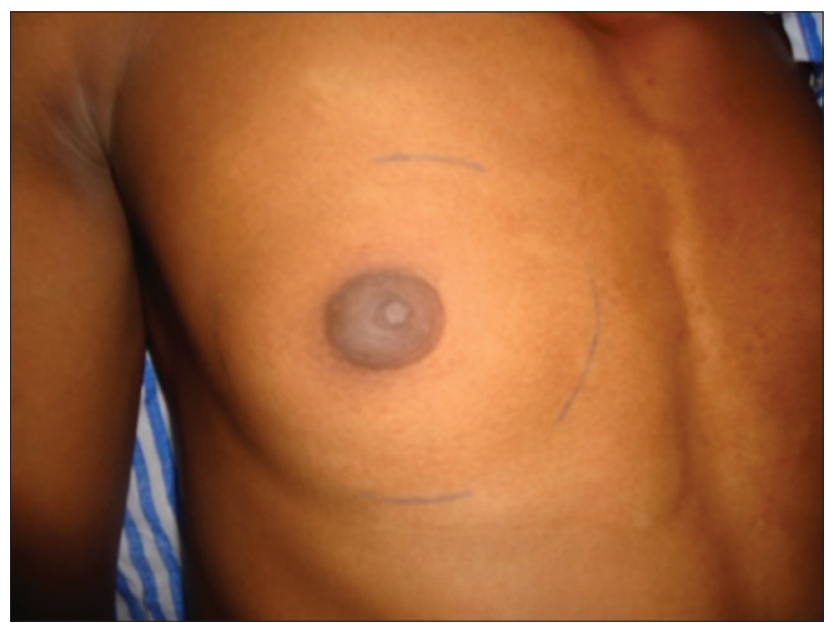

Figure 2a: Preop photograph showing right sided gynecomastia

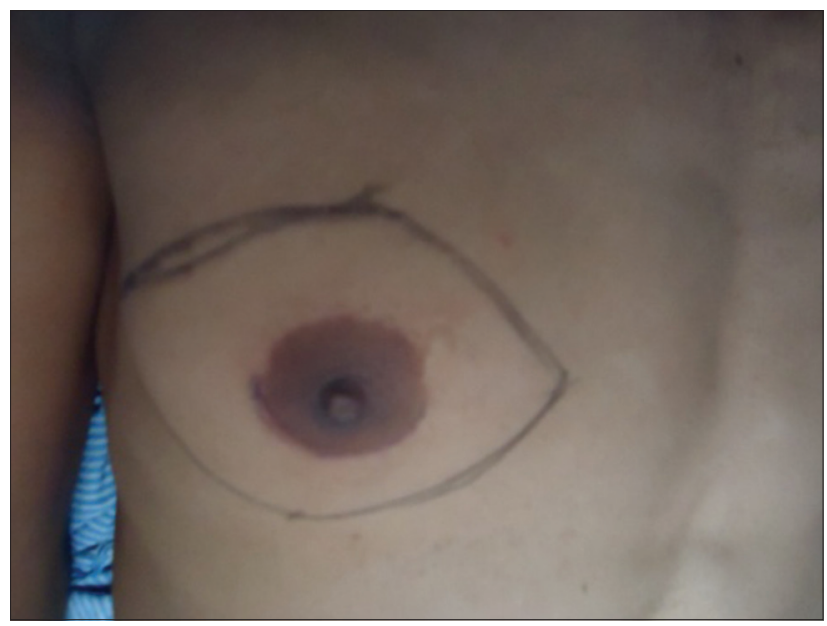

Figure 3a: Preop photograph showing right sided gynecomastia

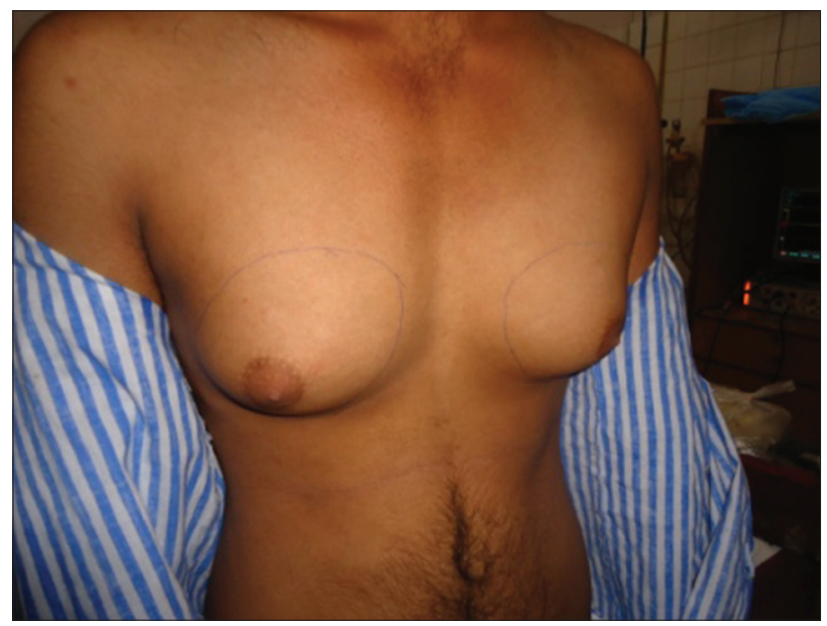

Figure 4a: Preop photograph showing bilateral gynecomastia

first-line treatment for pseudogynecomastia (Simon grade 1,2 [Table 1$]^{[3,17]}$ while subcutaneous mastectomy alone, liposuction alone, or liposuction combined with subcutaneous mastectomy have been described for the 


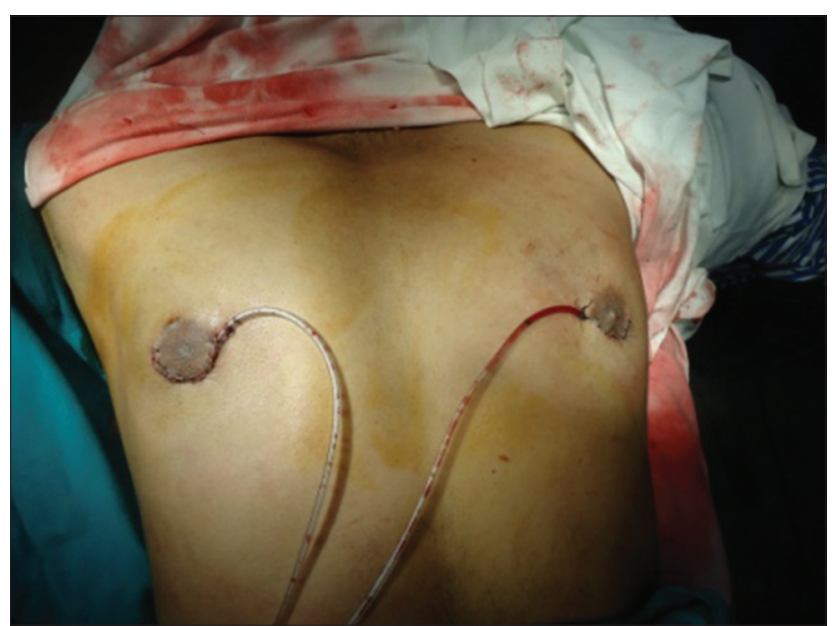

Figure 4b: Immediate postop photograph with both the suction drain in situ taken through the respective incision

\begin{tabular}{ll}
\hline \multicolumn{2}{l}{ Table 1: Simon's classification for gynecomastia } \\
\hline Grade & Features \\
\hline 1 & Mild enlargement with no skin redundancy \\
2 & 2a: Moderate enlargement with no skin redundancy \\
& 2b: Moderate enlargement with minor skin redundancy \\
3 & Marked enlargement with marked skin redundancy \\
\hline
\end{tabular}

surgical treatment of true gynecomastia (grade 1 and 2). In this series, all the patients were in grade 1 and 2 categories. Therefore, no patients required skin removal.

In our series, two patients of pseudogynecomastia were treated with liposuction alone whereas the rest of the cases were of true gynecomastia that required both liposuction and subcutaneous mastectomy. Suction assisted lipectomy is easy to perform, which does not interfere with vascularity of areola and gives good cosmetic results with minimal complication in terms of hematoma. ${ }^{[3,8]}$

Nevertheless, the use of suction-assisted lipectomy in true gynecomastia is one of the controversial issue. ${ }^{[17]}$ Some researchers suggest to use ultrasound-assisted liposuction or specialized cannulae for the surgical treatment of true gynecomastia. ${ }^{[18-20]}$ We did not get an opportunity to use these modalities due to the unavailability of such facilities at our Centre.

Several authors recommend the use of subcutaneous mastectomy for the treatment of true gynecomastia ${ }^{[6,21,22]}$ but, due to disappointing results and various complications, its use alone is avoided.

For subcutaneous mastectomy, a number of incisions have been described and used by various investigators. Transareolar incision was introduced by Pitanguy, ${ }^{[23]}$ superior semicircular, intra-areolar incision by Letterman and Schurter ${ }^{[1]}$ and Webster described the intraareolar incision, the periareolar, and circumareolar incisions. Since the invention of Webster's incision, it has widely been used due to its most cosmetically acceptable appearance.

In our series, we also used Webster's semicircular infraareolar incision, through which, both the procedure liposuction and subcutaneous mastectomy were performed. Use of liposuction may lead to an unacceptable contouring, asymmetry, residual skin and glandular tissue. ${ }^{[8]}$

Subcutaneous mastectomy has its own complications. Colombo-Benkmann et al ${ }^{.24]}$ in their series, find incidence of hematoma formation in $11.4 \%$ of patients while hyposthesia, hypertrophic scar and retraction of skin was noted in 53\% of patients.

Dolsky finds no complication in using liposuction combined with subcutaneous mastectomy in his series. ${ }^{[25]}$ We, in our series, noted no case of hematoma or seroma formation. However, two patients developed infection whereas two others experienced contour deformity.

In terms of psychological outcome, Gabra et al. finds that, $85 \%$ patients were satisfied with the results of their series. ${ }^{[26]}$ This corresponds to our results, which is showing $86 \%$ satisfaction rate.

\section{CONCLUSION}

Liposuction combined with subcutaneous mastectomy is a reliable, versatile, less time consuming and valid procedure for the treatment for gynecomastia. This procedure provides satisfactory aesthetic results.

\section{REFERENCES}

1. Letterman G, Schurter M. Suggested nomenclature for aesthetic and reconstructive surgery of the breast. Part 3: Gynecomastia. Aesthetic Plast Surg 1986;10:55-7.

2. Matarasso SL. Liposuction of the chest and back. Dermatol Clin 1999;17:799-804.

3. Celebioğlu S, Ertaş NM, Ozdil K, Oktem F. Gynecomastia treatment with subareolar glandular pedicle. Discussion, 287. Aesthetic Plast Surg 2004;28:281-6.

4. Wassersug RJ, Oliffe JL. The social context for psychological distress from iatrogenic gynecomastia with suggestions for its management. J Sex Med 2009;6:989-1000.

5. Park AJ, Lamberty BG. Gynaecomastia: Have Webster's lessons been ignored? J R Coll Surg Edinb 1998;43:89-92.

6. Noer HH, Søe-Nielsen NH, Gottlieb J, Partoft S. Gynecomastia treated by subcutaneous mastectomy using Webster's method. Ugeskr Laeger 1991;153:578-80.

7. Courtiss EH. Gynecomastia: Analysis of 159 patients and current recommendations for treatment. Plast Reconstr Surg 1987;79:740-53.

8. Pitman GH. Liposuction and aesthetic surgery. St. Louis: Quality Medical Publishing Inc; 1993. p. 197-209. 
9. Illouz YG. Body contouring by lipolysis: A 5-year experience with over 3000 cases. Plast Reconstr Surg 1983;72:591-7.

10. Teimourian B, Perlman R. Surgery for gynecomastia. Aesthetic Plast Surg 1983;7:155-7.

11. Lewis CM. Lipoplasty: Treatment for gynecomastia. Aesthetic Plast Surg 1985;9:287-92.

12. Samdal F, Kleppe G, Amland PF, Abyholm F. Surgical treatment of gynaecomastia. Five years' experience with liposuction. Scand J Plast Reconstr Surg Hand Surg 1994;28:123-30.

13. Gasperoni C, Salgarello M, Gasperoni P. Technical refinements in the surgical treatment of gynecomastia. Ann Plast Surg 2000;44:455-8.

14. Hands LJ, Greenall MJ. Gynaecomastia. Br J Surg 1991;78:907-11.

15. Einav-Bachar R, Phillip M, Aurbach-Klipper Y, Lazar L. Prepubertal gynaecomastia: Aetiology, course and outcome. Clin Endocrinol (Oxf) 2004;61:55-60.

16. Braunstein GD. Gynecomastia. N Engl J Med 1993;328:490-5.

17. Stark GB, Grandel S, Spilker G. Tissue suction of the male and female breast. Aesthetic Plast Surg 1992;16:317-24.

18. Rigg BM. Morselization suction: A modified technique for gynecomastia. Plast Reconstr Surg 1991;88:159-60.

19. Samdal F, Kleppe G, Aabyholm F. A new suction-assisted device for removing glandular gynecomastia. Plast Reconstr Surg 1991;87:383-5.

20. Graf R, Auersvald A, Damasio RC, Rippel R, de Araújo LR, Bigarelli LH, et al. Ultrasound- assisted liposuction: An analysis of 348 cases. Aesthetic Plast Surg 2003;27:146-53.

21. Steele SR, Martin MJ, Place RJ. Gynecomastia: Complications of the subcutaneous mastectomy. Am Surg 2002;68:210-3.

22. Colonna MR, Baruffaldi Preis FW, Ponzielli G, Cavallini M, Giovannini UM, Di Leo A. Gynecomastia: Diagnostic and surgical approach in the treatment of 61 patients. Ann Ital Chir 1999;70:699-702; discussion 702-3.

23. Pitanguy I. Transareolar incision for gynecomastia. Plast Reconstr Surg 1966;38:414-9.

24. Colombo-Benkmann M, Buse B, Stern J, Herfarth C. Indications for and results of surgical therapy for male gynecomastia. Am J Surg 1999;178:60-3.

25. Dolsky RL. Gynecomastia. Treatment by liposuction subcutaneous mastectomy. Dermatol Clin 1990;8:469-78.

26. Gabra HO, Morabito A, Bianchi A, Bowen J. Gynaecomastia in the adolescent: A surgically relevant condition. Eur J Pediatr Surg 2004;14:3-6.

How to cite this article: ${ }^{* *}$

Source of Support: Nil, Conflict of Interest: None declared 